\title{
Critical factors in implementing the ISSA Guidelines on return to work and re-integration in developing world contexts
}

\author{
Marius Olivier \\ International Institute for Social Law and Policy, University of Western Australia, Australia. marius.olivier@uwa.edu.au \\ Avinash Govindjee \\ Nelson Mandela Metropolitan University, South Africa. Avinash.Govindjee@nmmu.ac.za
}

The International Social Security Association (ISSA) "Guidelines on Return-to-Work and Reintegration" (the Guidelines) chronicles good practice models, policies and procedures which have successfully been implemented by social security institutions in respect of return-to-work and reintegration. Models have specifically been developed by ISSA in order to identify approaches that will enable decision-makers in social security institutions to benefit from global experience in this area. In particular, the Guidelines are designed to: outline strategic options for social security institutions in order to achieve these outcomes; stimulate discussion around good practice returnto-work programmes for social security institutions; identify critical success design elements; and offer practical implementation tools.

Return-to-work of occupationally injured and diseased workers, and the management of their disabilities, is an area clearly in need of reform in the developing world. The proposed contribution focuses on the recent experiences of two middle-to-high income developing countries, namely Malaysia and South Africa, who are at different stages of introducing and implementing detailed return-to-work measures. The paper considers salient aspects of the seven "Specific Return-to-work Principles and Guidelines" (the Specific Guidelines, contained in Part B of the Guidelines) and matches these against the approaches adopted / being adopted by Malaysia and South Africa respectively. This methodology is designed to provide a comparative, context-specific sample of the application of selected issues emerging from the Specific Guidelines in order to provide some pointers for purposes of extrapolating how return-to-work and reintegration might be introduced and implemented in other (middle-to-high income) countries in the developing world.

The paper acknowledges the tremendous challenges faced by developing countries in introducing and implementing return-to-work and reintegration arrangements, but focuses instead on the application of Specific Guidelines such as "early intervention" and an "individualized approach" in Malaysia and South Africa. The paper draws on constitutional frameworks, draft and existing legislation, policy statements and judicial precedent in order to demonstrate the extent to which the two countries have already been able to integrate selected best practice principles, which are now contained in the Specific Guidelines, in their respective approaches. The paper accordingly holds the potential to demonstrate that the sentiments contained in the Guidelines are practically implementable and ought, therefore, to be carefully considered and analysed by other countries seeking to introduce similar return-to-work and rehabilitation initiatives. 